application to fields as diverse as the algebraic theory of invariants and modern quantum mechanics. Littlewood's work is in the direct line of tradition associated with the names of Frobenius, Alfred Young, and Schur; and his book, "The Theory of Group Characters" published in 1940, is a standard work on the subject. In recent papers, Littlewood. has developed a calculus of a class of symmetric functions known as Schur functions which have recently been shown to have extensive applications in invariant theory.

\section{Promethium, the New Name for Element 6I}

At a symposium held by the American Chemical Society at Syracuse University on June 30, J. A. Marinsky and L. E. Glendenin, who during the War had succeeded in separating element 61 from the other uranium fission products, proposed to christen this element 'promethium'. They explained their choice by a reference to Prometheus, "who stole fire from heaven for the use of mankind and for his audacity was chained to a mountain by the gods and set upon by vultures. This name not only symbolizes the dramatic way in which the element may be produced in quantity as a result of man's harnessing of the energy of nuclear fission, but also warns man of the impending danger of punishment by the vulture of war." In a review published some eighteen months ago (Nature, 159, 8; 1947) the conclusion was reached that Prof. C. D. Coryell's group, to which Marinsky and Glendenin belong, had the strongest claim to the discovery of element 61 and was entitled to give it a name. Some may perhaps think the present proposal a little far-fetched, since there are more impressive effects of atomic energy known than the production of small quantities of a new rare earth, and classical students may take exception to the vultures-since Prometheus' quarrel was with Zeus, the bird sent by his antagonist to torture him was, naturally, an eagle; but the etymology of this new name will soon be of as little importance as that of dozens of other element names which are much less appropriate. There are still the rival claims for 'illinium' and, more recently, for 'cyclonium' (see Chemical and Engineering News, 25, 2555; 1947), and it is, therefore, too early to say whether the chemists of Coryell's group will be generally recognized as the discoverers of element 61 ; but their brilliant work seems to merit this international recognition, and there is a great likelihood that promethium (symbol $\mathrm{Pm}$ ) will take its permanent place in the table of the chemical elements.

\section{Commonwealth Plant Breeders' Meeting}

AN informal meeting of Commonwealth plant breeders was held at the School of Agriculture, Cambridge, during June 24-25. Representatives from Australia, Canada, England, Malaya, New Zealand, Northern Ireland, Scotland, Sierra Leone, South Africa, Sudan, Tanganyika and Wales were present; Dr. P. S. Hudson, director of the Commonwealth Bureau of Plant Breeding and Genetics, acted as chairman. The proceedings of the meeting included a review by Dr. P. S. Hudson and Mr. R. H. Richens of the work of the Commonwealth Bureau of Plant Breeding and Genetics since the last similar meeting, short reports by the delegates of the principal lines along which plant breeding is developing in the various Commonwealth countries, and an account by Dr. P. S. Hudson of the results of the meeting held at Washington last April, between the Food and Agriculture
Organisation, the Commonwealth Agricultural Bureaux, the U.S. Department of Agriculture and other bodies, on genetic stocks. Among the resolutions passed at the meeting, several deprecated any reduction in the number or length of the abstracts appearing in Plant Breeding Abstracts, the periodical published by the Commonwealth Bureau of Plant Breeding and Genetics; support was given to a proposal to institute a standing inquiry service whereby plant breeders should be sent details at regular intervals of all published articles bearing on their own field of research; and suggestions were made to provide for an efficient service for the maintenance of genetic stocks of crop plants. The proceedings of the meeting will be circulated to the delegates and to other interested bodies.

\section{Olympic Torches}

THE Organising Committee of the XIVth Olympiad approached the Department of Scientific and Industrial Research in 1946 for assistance and advice on the design of a torch to be carried by relays of runners across Europe from the plain of Olympia to Wembley Stadium in London, and on the most suitable fuel. This problem was undertaken by the Fuel Research Station, and the actual investigation was carried out by Dr. L. R. B. Shackleton. After many trials, it was decided that the most suitable fuel was hexamine in the form of tablets. Hexamine gives a non-luminous flame, and to make the flame visible in all weathers 6 per cent of naphthalene was added. The fuel was manufactured by Promedico Products, Ltd., 22, Turle Road, London, N.4. Prototype torches made at the Fuel Research Station were tried out by runners, first from the South London Harriers and, after certain modifications in design, by officers from the Royal Naval College, Greenwich. In the final design of the torch, seven tablets are enclosed in a perforated metal cylinder with an inner sleeve concealing the lower three tablets. As the upper tablets burn away, the lower reserves are forced up into the burning zone by a spring. In order to facilitate lighting, the Wessex Aircraft Engineering Co., Ltd., Salisbury, provided a tablet of nitrate composition which was introduced on top of the fuel pack. A quick-match, provided for ignition, protruded through the perforated container. One or two final refinements were introduced at the concluding stages to safeguard the effectiveness of the torches during transport to the various countries through which the relay runners had to pass. The fuel tablets were totally enclosed in a nitro-cellulose cover provided by Cascelloid, Ltd., High Holborn, London. This cover burned immediately on ignition, leaving no carbon residue. The perforated metal fuel container was also capped and sealed with adhesive tape. Both of these precautions were considered necessary to preserve the fuel and to avoid any risks of accidental ignition.

\section{Museum of the History of Science, Oxford}

Since 1940 the Museum of the History of Science, Oxford, has been making inquiries as to the whereabouts of a number of valuable and irreplaceable objects which had been stored at the beginning of the War by the late curator of the Museum, Dr. R. T. Gunther. These included the oldest dated instrument in the world, an astrolabe dated A.D. 984, the astrolabes of Queen Elizabeth and Archbishop Laud, the sundial made by Nicolaus Kratzer for Cardinal Wolsey, and many other treasures. Dr. Gunther died without revealing the place where he had stored these 